\title{
REFLEXÕES SOBRE A LEI GERAL TRIBUTÁRIA*
}

\author{
João Gamboa Cardina**
}

A Lei Geral Tributária vem colmatar uma lacuna existente no sistema fiscal português e visa três objectivos: o acolhimento dos princípios do direito fiscal previstos na Constituição da República Portuguesa ou lei ordinária, os poderes da Administração Tributária e as garantias dos contribuintes.

As sucessivas revisões constitucionais que aprofundaram as garantias dos administrados, a intensificação da concorrência nacional $e$ internacional que necessita de maior certeza e segurança de actuação da Administração Tributária e contribuintes, o desenvolvimento económico $e$ a globalização da economia que podem favorecer contornos de fraude $e$ evasão fiscal, impunham uma nova lei para dar coerência e estabilidade ao sistema fiscal, reforçar as garantias dos contribuintes e imprimir maior eficácia à Administração Tributária. Esta lei, já conhecida pela Constituição Material da Fiscalidade, define simultaneamente um conjunto de princípios dirigidos ao legislador tributário, aos contribuintes e à Administração Tributária.

A Lei Geral Tributária contempla bastantes inovações que traduzem alguma ruptura relativa com o sistema fiscal vigente, não devendo ser vista como uma sistematização e aperfeiçoamento das normas fundamentais do direito tributário. A sua introdução constitui uma ferramenta fundamental para um novo ciclo de relações entre Fisco - contribuinte, uma colaboração recíproca entre a Administração Tributária e os contribuintes com base no princípio da boa fé, na transparência e objectividade na

** Assistente do Pólo de Viseu do Centro Regional das Beiras da Universidade Católica Portuguesa. 
tributação e na realização dos objectivos da justiça - princípios plasmados na nova lei e que se reflectirão em todo o sistema fiscal.

A eficácia e eficiência deste diploma dependerá da substituição do actual Código do Processo Tributário que contém cerca de cinquenta normas revogadas, da adaptação dos códigos fiscais e demais legislação tributária à nova lei e da publicação de um Regime Juridico das Infrações Fiscais, cujos trabalhos preparatórios já se encontram bastante adiantados.

Eis alguns dos aspectos tratados no presente trabalho.

\section{INTRODUÇÃO}

Desde 1970 que existe projecto da Lei Geral Tributária, mas que nenhuma reforma fiscal acolheu, mesmo a que se efectuou em 1989. Existia uma lacuna no sistema fiscal português, que se encontra preenchida em outros países da União Europeia e que suscitava problemas de coerência interna, considerando que a Constituição da República Portuguesa consagra o Título IV ao Sistema financeiro e fiscal.

Em 1997, com a resolução do Conselho de Ministros $n^{\circ} .119 / 97$, de 14 de Julho, o Governo assume o desenvolvimento do sistema fiscal e o aperfeiçoamento da reforma fiscal, onde se prevê o papel determinante que cabe a uma Lei Geral Tributária.

Na tributação indirecta, devido à conjuntura e critérios de Maastrich, por iniciativa do Governo, procedeu-se à alteração de pontos fulcrais do Imposto sobre o valor acrescentado (IVA), criando-se a taxa intermédia, a passagem de bens para outras taxas e houve alteração dos prazos estabelecidos no Código do Imposto sobre valor acrescentado (CIVA). Neste código continua também a existir uma lacuna, ou seja, a ausência da criação do regime forfetário do IVA, que mais tarde ou mais cedo tem de ser adoptado.

$\mathrm{O}$ artigo $53^{\circ}$. do CIVA necessita de ser reformulado, imprimindo novo tratamento aos pequenos contribuintes, que no âmbito declarativo deve ser idêntico ao do Imposto sobre o rendimento das pessoas singulares (IRS).

Os impostos sobre os automóveis, tabacos e produtos petrolíferos foram alterados e está prevista a publicação de um novo código do imposto do selo.

A directiva sobre bens em segunda mão ainda não está a ser totalmente aplicada no direito interno.

No imposto sobre o rendimento pessoal acabou-se com o splitting mitigado, os abatimentos foram convertidos em deduções à colecta, alterou-se o regime das mais-valias e todos os contribuintes são obrigados a declararem os seus rendimentos para que, segundo o Governo, "não se esconda muita 
fraude e evasão". No Imposto sobre o rendimento das pessoas colectivas (IRC) procedeu-se à baixa da taxa e há necessidade de aproximar as linguagens de IRC e IRS.

No imposto sobre o património deve avançar a informatização da autárquica e efectuar-se o debate sobre as conclusões do relatório para a reforma do imposto sobre o património.

Devido à Lei Geral Tributária publicar-se-á um novo Código do Processo Tributário, que deverá ser comum às Alfândegas, bem como a fusão do Regime Jurídico das Infracções Fiscais e adaptação dos demais códigos.

Neste simples e reduzido documento com muitas imperfeições, das quais nos penitenciamos, agravadas pelo escasso tempo em que foi elaborado, analisam-se muito sucintamente os grandes princípios do direito fiscal português, os poderes da Administração Tributária e as garantias dos contribuintes - matéria acolhida pela Lei Geral Tributária. A definição de conceitos cabe à doutrina e jurisprudência e não à lei, inserindo-se, por isso mesmo, os conceitos mais pertinentes defendidos por ilustres juristas e que a jurisprudência normalmente não tem posto em causa.

\section{JUSTIFICAÇÃO DA LEI GERAL TRIBUTÁRIA}

A Resolução do Conselho de Ministros $n^{\circ}$ 119/97, de 14 de Julho, assinalaria, na alínea b) do $\mathrm{n}^{\circ} .3$ do Ponto $8^{\circ}$, o papel determinante que deve assumir na reforma fiscal uma Lei Geral Tributária, “ onde se estabelecerão os princípios fundamentais do Direito Tributário, sistematizando-se, uniformizando-se e clarificando-se diversas matérias, nomeadamente, o posicionamento da administração fiscal e aduaneira perante os contribuintes, o sistema de garantias dos contribuintes, o regime jurídico de enquadramento da norma tributária, a teoria geral da relação jurídico-tributária e seus elementos constitutivos, a tipologia dos tributos e respectivo regime jurídico, a definição da obrigação principal e das obrigações acessórias dos contribuintes, o regime da responsabilidade, o regime básico da avaliação e as formas de extinção da relação jurídica tributária". A Lei ${ }^{\circ}$. $41 / 98$, de 4 de Agosto, autoriza o Governo a publicar uma Lei Geral Tributária donde constem os grandes princípios substantivos que regem o direito fiscal português e uma definição mais precisa dos poderes da Administração e das garantias dos contribuintes.

O Decreto-Lei $n^{\circ}$. 398/98, de 17 de Dezembro aprovou a Lei Geral Tributária que entrou em vigor no dia 1 de Janeiro de 1999, tendo o Governo afirmado que a presente lei é a reforma das reformas.

A ausência de um diploma desta natureza constituía uma grande lacuna do sistema fiscal português, o que não sucede em outros países como a 
Alemanha, Moçambique, Espanha e até Angola nos anos 60. Em Espanha, a sua Lei Geral Tributária é criada pela Lei 230/1963, de 28 de Dezembro, publicada no Boletin Oficial del Estado de 31 de Dezembro de 1963, e em Portugal existiu um projecto em 1970, mas foi algo que a reforma fiscal de 1989 não levou avante.

A Constituição da República Portuguesa tem um capítulo para o sistema fiscal que faz parte da Constituição Financeira. A Lei Geral Tributária é a Constituição Material da Fiscalidade. Esta lei ainda terá mais importância aquando da alteração aos códigos e na consolidação dos Regimes de infraç̧ões e benefícios fiscais.

Contemplando esta lei cerca de 50 inovações, é importante a forma como os aplicadores introduzam as inovações e as interiorizem. A LGT não tem continuidade, mas traços de clivagem que traduzem alguma ruptura relativa $\mathrm{e}$ como consequência implica um estado de abertura de todos os aplicadores da norma.

Não há apenas questões garantísticas, estabelecendo a lei um equilíbrio, no patamar superior, entre as garantias dos contribuintes e as prerrogativas da Administração Tributária. Não se duvida que a Lei pode ser aperfeiçoada, e melhorada na elaboração do novo Código do Processo Tributário, realçando apenas um exemplo no que concerne à cláusula de anti-abuso que deve figurar na LGT e não no CPT.

\section{ELEMENTOS ESTRUTURANTES DA LEI GERAL TRIBUTÁRIA}

A Lei Geral Tributária não tem prevalência sobre as restantes leis, não podendo considerar-se lei reforçada como acontece com a Lei das Finanças Locais, Lei de Enquadramento do Orçamento do Estado ou mesmo do Código do Procedimento Administrativo. São revogados artigos do Código do Processo Tributário (cfr. Artigo $2^{\circ}$. do Decreto-Lei $\mathrm{n}^{\circ}$. 398/98, de 17 de Dezembro) e a Lei Geral Tributária cria cisão do referido Código, mas não revoga normas especiais, nem normas de Direito Comunitário. A Lei Geral Tributária consagra os princípios fundamentais do sistema fiscal (cfr. artigos $5^{\circ}$., $6^{\circ}$., $7^{\circ}$. e $8^{\circ}$.), acolheu normas constitucionais, mas não pode interpretar a Constituição da República Portuguesa e não regula as taxas, porque a doutrina está insuficientemente desenvolvida, existindo alguma penumbra entre taxas e impostos.

O legislador estruturou a presente lei com base em Títulos (cinco), Capítulos, Secções e Subsecções. O Título I contém os princípios gerais e fundamentais da ordem tributária, o acolhimento das normas constitucionais fiscais e a clarificação da aplicação das leis tributárias no tempo e no espaço. 
O Título II regula a relação jurídica tributária, que inclui os sujeitos das relações tributárias e a responsabilidade tributária, o objecto, a constituição e modificação da relação jurídica tributária, a extinção desta, através do pagamento, dação em cumprimento, caducidade do direito à liquidação e da prescrição e, por último, a definição da garantia da prestação tributária.

No Título III, é regulado o procedimento tributário procedendo-se à adequação ao Código do Procedimento Administrativo, sem esquecer o desenvolvimento e aprofundamento das garantias dos cidadãos objecto da $4^{\circ}$. Revisão Constitucional. Este Título ainda regulamenta os procedimentos da inspecção tributária, embora remeta para diploma regulamentar próprio o exercício de tal direito. Prevê também os procedimentos de avaliação da matéria tributável e pedido de revisão da mesma.

O Título IV, na esteira da $4^{a}$. Revisão da Constituição, consagra o acesso à justiça tributária, definindo os princípios fundamentais do processo judicial tributário, desde a impugnação até ao processo de execução fiscal, que com a presente lei se transformou em processo judicial.

Por último, o Título $\mathrm{V}$ enuncia os princípios do sistema sancionatório tributário, definindo a responsabilidade das pessoas colectivas e dos seus responsáveis.

\section{OS PRINCÍPIOS DO SISTEMA FISCAL}

A exemplo do que sucede em outros países, a Lei Geral Tributária estabelece as linhas fundamentais e a estrutura do sistema fiscal português. A classificação dos tributos, seus pressupostos e clarificação da função das contribuições especiais constam igualmente da presente lei. Os tributos compreendem os impostos, incluindo os aduaneiros e especiais, as taxas e demais contribuições financeiras a favor de entidades públicas e, quanto à sua natureza, podem ser fiscais e parafiscais e, quanto ao sujeito activo, classificam-se em estaduais, regionais e locais.

Não é pretensão de um diploma desta natureza consagrar conceitos por via legal, função que cabe à doutrina que deverá debater e desenvolver tal matéria. Estas normas têm como objectivo habilitar o intérprete do Direito Tributário com ferramentas para a sua aplicação e diminuir a incerteza e a insegurança na actividade tributária, razão pela qual se abordarão aqui alguns conceitos.

Tributo é "a prestação patrimonial definitiva estabelecida por lei a favor de uma entidade que tem a seu cargo o exercício de funções públicas, para satisfação de fins públicos, que não constituam sanção de actos ilícitos". Nesta definição cabem os impostos, as taxas e contribuições especiais que são verdadeiros impostos (cfr. $\mathrm{n}^{\circ}$. 3 do artigo $4^{\circ}$. da LGT). Assim, imposto 
consiste na "Prestação patrimonial definitiva e unilateral, estabelecida por lei a favor de uma pessoa colectiva de direito público, para a realização de fins públicos, e a qual não constitui sanção de um acto ilícito". Analisando ambos os conceitos, a diferença entre tributo e imposto está no carácter unilateral do último. Significa que sendo o imposto uma prestação unilateral ou não sinalagmática, não dá direito ao devedor de exigir qualquer contraprestação, contrariamente ao que acontece com as taxas que têm carácter bilateral e dão lugar a benefícios individualizados em contrapartida dos montantes pagos.

O imposto é caracterizado pelo elemento objectivo, elemento subjectivo e elemento teleológico. Segundo Sá Gomes, objectivamente o imposto é:

a) Uma prestação patrimonial (avaliável em dinheiro como acontece no imposto do selo na prestação "de facere" e no imposto sucessório quando se verifica a dação em cumprimento), não sendo de todo correcto a utilização da expressão "prestação pecuniária".

b) Definitiva, ou seja, não dá direito de restituição, reembolso ou indemnização, distinguindo-se dos "Empréstimos Públicos Forçados", "Requisição Administrativa" e "Expropriação por Utilidade Pública".

c) Unilateral pelos motivos já enunciados.

d) Estabelecida por lei, ou seja, o imposto tem sempre como fonte a lei, razão pela qual certos autores se referem à natureza coactiva do imposto, afirmação que deixa algumas dúvidas, porquanto depende dos particulares colocar-se ou não na situação geradora da obrigação de pagar imposto.

e) Não constitui sanção de um acto ilícito. Este elemento distingue o imposto das sanções patrimoniais (v.g. coimas, multas e juros fiscais) que visam punir as violações da lei.

O elemento subjectivo do imposto está subjacente aos sujeitos activos da relação jurídica tributária. A prestação é estabelecida a favor de uma pessoa colectiva de direito público, o que não implica que os sujeitos passivos sejam sempre os particulares, nomeadamente no Imposto sobre o Valor Acrescentado, onde pessoas colectivas de direito público também podem ser sujeitos passivos das relações tributárias.

Elemento teleológico. O imposto define-se ainda pelo fim a que se destina e tem os seguintes objectivos:

a) Satisfação das despesas públicas.

b) Redistribuição da riqueza.

c) Função social.

d) Protecção de determinadas empresas ou actividades com a finalidade da sua expansão e desenvolvimento económico.

e) Interligação com o investimento, poupança, inflação, consumo e demais variáveis económicas. 
O pressuposto dos impostos assenta essencialmente na capacidade contributiva, enquanto que a contraprestação é o típico pressuposto das taxas. Existe uma distinção entre os tributos e outras prestações financeiras, que por não terem essa natureza não são acolhidas pela Lei Geral Tributária; mas esta lei abrange as contribuições especiais que cada vez mais adquirem maior relevo com as obras públicas (v.g. Expo 98, Ponte Vasco da Gama e modernas redes viárias), cujas mais-valias adquiridas por seu intermédio devem ser tributadas, por se considerarem verdadeiros impostos.

\section{PRINCÍPIOS FUNDAMENTAIS ACOLHIDOS NA CONSTITUIÇÃO OU PELA LEI ORDINÁRIA}

O Estado, Regiões Autónomas, Autarquias e demais pessoas colectivas de direito público exercem actividades tendentes a satisfazer necessidades públicas, nomeadamente a defesa, educação, saúde e justiça. De acordo com o Prof. Teixeira Ribeiro', o Estado produz três categorias de bens:

a) Bens que só satisfazem necessidades colectivas.

b) Bens que satisfazem necessidades colectivas $\mathrm{e}$ individuais gratuitamente ou a preço inferior ao custo.

c) Bens que satisfazem necessidades colectivas, necessidades individuais a preço igual ao custo ou preço superior ao custo, mas inferior ao do mercado, caso fossem entregues a entidades privadas, porque estas procuram o lucro.

Ainda, segundo o mesmo autor, existe uma grande diferença entre Finanças Públicas e Finanças Privadas, pois aquelas têm como meios de financiamento os impostos que não resultam de relações de troca, as receitas estão em função das despesas e não procuram o lucro. Ao contrário, as Finanças Privadas têm sócios e accionistas que financiam os capitais próprios das empresas, existem relações de troca e as despesas são função das receitas, devendo concorrer para a obtenção do rédito.

Tendo presente as Finanças Públicas, o Estado precisa de obter receitas para cobrir as despesas colectivas, necessita de dinheiro, de meios de financiamento para a satisfação das necessidades colectivas que têm vindo a aumentar, concretizando-se plenamente a Lei de Adolfo Wagner, financista alemão, que há um século definiu a lei do aumento das despesas públicas.

$\mathrm{O}$ artigo $103^{\circ} \cdot \mathrm{n}^{\circ} .1$ da Constituição da República Portuguesa estabelece que os impostos visam a satisfação das necessidades financeiras do Estado. $O$ $\mathrm{n}^{\circ}$. 2 do mesmo artigo define que os impostos são criados por lei que definirá a incidência, as taxas, os benefícios fiscais e as garantias dos contribuintes. $O$ sistema fiscal é da exclusiva competência da Assembleia da República (artigo 
$165^{\circ}$, alínea i, da C.R.P.). Dos normativos enunciados decorre o Princípio da Legalidade.

A incidência ( pressupostos donde resulta o nascimento do imposto) real $\mathrm{e}$ pessoal, a quantificação da matéria colectável, as normas de exclusão tributária (delimitação negativa da incidência), as taxas (factos de quantificação do imposto), benefícios fiscais e as garantias processuais graciosas e contenciosas, estão abrangidos pelo Princípio da Legalidade, sendo estabelecidos por lei material e formal emanada da Assembleia da República, contribuindo para uma melhor segurança e certeza da tributação².

O Princípio da Tipicidade Fechada ou taxativa também decorre do artigo $103^{\circ}$. já citado. Não são admitidos conceitos indeterminados e os factos objectos de tributação devem estar tipificados na incidência. Na determinação dos elementos essenciais do imposto não são permitidos poderes discricionários à Administração Tributária. Com a discricionaridade, não se deve confundir a margem livre de apreciação na determinação da matéria colectável, devendo, nestes casos, a Administração Tributária aplicar a solução mais justa, ou seja, a única solução querida pela lei. A última reforma fiscal, no âmbito do IRS e IRC, reduziu bastante a margem de livre apreciação, também conhecida por discricionaridade técnica.

Os artigos $13^{\circ}$. e $104^{\circ}$. da Constituição da República Portuguesa estabelecem o Princípio da Igualdade. Existe a igualdade tributária como princípio geral do Direito Fiscal e a igualdade jurídica como princípio jurídico. A igualdade jurídica contém uma vertente formal e uma vertente material, estabelecendo a primeira a igualdade dos cidadãos perante a lei e a segunda a proibição de discriminações arbitrárias. Na igualdade tributária, como um princípio material, ainda se distitgue o princípio da generalidade (igualdade fiscal subjectiva) e o princípio da uniformidade (igualdade fiscal objectiva), que prevê a igualdade horizontal (tributação igual, para riqueza igual) e a igualdade vertical (tributação diferente, para riqueza diferente) ${ }^{3}$. Analisando o artigo $104^{\circ}$. da Constituição, coloca-se a questão de saber se este normativo não será contra o Princípio da Igualdade. Esta norma tem a ver com a capacidade contributiva e a articulação de prioridades funcionais e hierarquização de objectivos políticos e económicos. O esforço fiscal deve ser idêntico em todos os contribuintes, existindo uma igualdade de sacrifícios como apanágio da capacidade contributiva, que deve ser complementada com a utilidade marginal.

Alguns autores afirmam que os rendimentos presumidos ou a colecta mínima distorcem o Princípio da Igualdade, embora na última reforma fiscal tenha havido muita prudência no tratamento destas situações. No entanto, certos fiscalistas dizem que a tributação do rendimento real das empresas é uma ficção, porque a valorização das existências, a aplicação do regime das 
reintegrações e a disciplina das provisões não conduzem a um rendimento real, mas presumido.

Existem alguns desvios ao Princípio da Igualdade, nomeadamente desagravamentos fiscais por razões objectivas e subjectivas, agravamentos fiscais por razões de interesse público e isenções individuais. São situações pontuais com carácter social ou económico que não afectam o Princípio Constitucional da Igualdade Tributária ${ }^{4}$.

Da Constituição decorre também o Princípio da Eficácia e da Eficiência. Lido indirectamente $\mathrm{o}$ artigo $103^{\circ} . \mathrm{n}^{\circ} .1$ temos que as necessidades financeiras do Estado e demais entidades públicas são satisfeitas através do sistema fiscal que deverá proporcionar as receitas para tal desiderato. $O$ sistema fiscal necessita de meios para ser eficaz e eficiente na sua actuação. Devem existir mecanismos de repressão da evasão e fraude fiscal, existência de medidas anti-evasivas e necessidade de conceitos próprios e elaborados, embora seja de afastar que os regulamentos internos, circulares e ofícios-circulares, o chamado "direito circulatório" se sobreponha à lei.

$\mathrm{O}$ artigo $104^{\circ}$. da Constituição define a tributação do rendimento pessoal e das empresas, a tributação do património e a tributação do consumo, mas os respectivos códigos fiscais ainda não se encontram totalmente adaptados a este preceito constitucional.

Para além das necessidades financeiras do Estado, a tributação deve promover a justiça social, a igualdade de oportunidades e a correcção das desigualdades na distribuição da riqueza e do rendimento. No imposto sobre o rendimento das pessoas singulares (IRS), a tributação deve atender à doença, velhice ou outros casos de redução da capacidade contributiva. $\mathrm{O}$ agregado familiar não pode ser discriminado, não devendo resultar tributação mais gravosa do conjunto dos rendimentos do que resultaria da tributação autónoma das pessoas que o constituem.

Igualmente a tributação deve favorecer o emprego e os bens de primeira necessidade, o que tem vindo a acontecer com o desagravamento das taxas do Imposto sobre o rendimento das pessoas colectivas (IRC) e do imposto sobre o Valor Acrescentado sobre bens e serviços que passaram de $17 \%$ para $12 \%$ e os mais essenciais passaram para a lista da taxa reduzida.

A tributação deve favorecer a formação do aforro e do investimento e tem um papel fulcral no desenvolvimento económico, estimulando a competitividade e a internacionalização da economia portuguesa no quadro de concorrência que deverá existir nas economias de mercado aberto.

A Lei Geral Tributária não podia deixar de acolher estes princípios (cfr. os seus artigos $5^{\circ}$. a $8^{\circ}$.), que para além de reforçarem a confiança dos contribuintes no sistema fiscal, traçam um rumo à actividade tributária. 


\section{INTERPRETAÇÃO E APLICAÇÃO DAS LEIS TRIBUTÁRIAS}

\subsection{Interpretação das Normas Tributárias}

A interpretação das normas obedece ao elemento literal ou gramatical (palavras da lei) e elemento lógico (mens legis, ou seja, o espírito da lei). $\mathrm{O}$ elemento lógico deve ser sistemático (a lei integra-se na ordem jurídica), racional (razão de ser e finalidade da lei - política, económica, financeira ou anti-evasiva) e histórico (projectos apresentados, discussões parlamentares, exposição de motivos ou diários parlamentares).

As normas podem ter interpretação declarativa (coincidência entre a letra e espírito da lei), interpretação extensiva (o intérprete conclui que o legislador disse menos do que queria dizer), interpretação restritiva (a letra da lei vai além do seu espírito, ou seja, o legislador disse mais do que queria) e interpretação correctiva (a letra e espírito estão em conflito, existindo divergência entre a palavra e o pensamento).

Existe a interpretação autêntica, quando feita pelo autor da norma interpretada ou por lei de valor igual ou superior à norma interpretada (cfr. artigo $112, \mathrm{n}^{\circ} .2$ da Constituição e artigo $13^{\circ}$. do Código Civil), interpretação doutrinal, quando efectuada pelos juristas e tribunais (cfr. artigo $13^{\circ}$. do Código Civil) e interpretação normativa, quando feita por fonte inferior à fonte interpretada, por regulamentos externos e regulamentos internos (circulares, ofícios ou despachos).

Quanto à interpretação da lei fiscal existem várias correntes. As expressões "in dubio contra fiscum" ou a inversa "in dubio pro fisco" são inaceitáveis com base nos princípios constitucionais já mencionados. Alguns críticos afastam a interpretação literal e não aceitam a interpretação extensiva por causa da analogia. Outros defendem que os elementos literal, sistemático e histórico devem ser ponderados face ao elemento racional ou ainda que se deve atender à interpretação funcional, sacrificando a letra da lei e discernir os tipos económicos da tributação, sendo possível a interpretação extensiva e analógica.

A melhor doutrina diz que as leis fiscais se devem interpretar como quaisquer outras, mas há proibição da analogia decorrente do princípio da tipicidade fechada e taxativa, não sendo possível a interpretação analógica e não se aplica o artigo $10^{\circ}$. do Código Civil. Em direito fiscal, os elementos essenciais do imposto não são susceptíveis da integração de lacunas através do recurso à analogia, porque punha em causa o valor da segurança e a protecção da confiança dada pelo Princípio da Legalidade.

A Lei Geral Tributária preocupou-se com a interpretação das normas tributárias, tendo em consideração a incerteza que resulta da falta de critérios precisos da interpretação das normas tributárias e de que demos nota, aquando 
das várias correntes existentes. $\mathrm{O}$ artigo $11^{\circ}$. consagra que são aplicadas as regras e princípios gerais de interpretação e aplicação das leis na interpretação das normas fiscais. Põe-se fim às interpretações arbitrárias das normas do direito fiscal, sendo legítimo o recurso à substância económica dos factos tributários se esgotados os meios comuns de interpretação das normas jurídicas, ainda persistir a dúvida sobre o sentido e alcance da norma. Este procedimento é comum nas leis tributárias estrangeiras já existentes. Por fim, são acolhidos os termos próprios dos restantes ramos do direito que sejam empregues nas normas fiscais, não se afastando o carácter de excepção, quando decorrer directamente da lei e a proibição de integração analógica.

\subsection{Aplicação da Lei Tributária no tempo}

Segundo o artigo $5^{\circ}$. do Código Civil, o início da vigência das normas é o fixado no diploma. Não havendo tal disposição, procede-se de acordo com a "vacatio legis", isto é a norma entra em vigor 5 dias após a publicação, no continente, 15 dias nas Regióes Autónomas e 30 dias em Macau e no estrangeiro.

A cessação da vigência da lei (artigo $7^{\circ}$. do Código Civil, embora muito deficiente) ocorre por limite temporal, por suspensão (caso do Imposto s/indústria agrícola e juros de suprimentos no Código do Imposto de Capitais), revogação expressa ou tácita, por desuso, por recusa da ratificação pela Assembleia da República, por declaração de inconstitucionalidade, por derrogação e por abrogação (revogação total). A revogação da lei revogatória não implica repristinação, salvo se a lei disser o contrário 5 .

Por razões de segurança dos cidadãos, estabilidade e confiança, não há retroactividade das leis (cfr. artigo $12^{\circ}$. do Código Civil e artigo $103^{\circ}$. da Constituição). A lei dispõe para o futuro.

A não retroactividade da lei fiscal não estava expressa na Constituição, decorrendo implicitamente do Princípio da Legalidade. Com a última Revisão Constitucional, o n. 3 do artigo $103 .^{\circ}$ passou a estabelecer que "ninguém pode ser obrigado a pagar impostos que não hajam sido criados nos termos da Constituição, que tenham natureza retroactiva ou cuja liquidação e cobrança se não façam nos termos da lei".

Tal princípio constitucional foi acolhido pela Lei Geral Tributária, que clarifica a aplicação da lei aos factos tributários de formação sucessiva, como acontece com o rendimento nos impostos que sobre este incidem. Quando as regras da matéria colectável tenham por função o desenvolvimento das normas de incidência observa-se a regra da irretroactividade, com base no seu carácter material (cfr. artigo $12^{\circ}$.). 


\subsection{Aplicação das normas fiscais no espaço}

Em matéria tributária, o princípio da territorialidade do imposto significa que o poder de tributar está internacionalmente limitado pela coexistência de outras soberanias, pelo que dentro do território esse poder pode ser exercido, salvo certas excepções ${ }^{6}$. A Territorialidade Pessoal não atende a elementos ligados objectivamente às manifestações de riqueza a tributar, mas sim à pessoa do contribuinte, domicílio, residência ou sede. A Territorialidade Real atende à situação dos bens, à localização dos consumos, à passagem das mercadorias nas fronteiras ou situações idênticas.

Mas a lei fiscal pode aplicar-se a factos ocorridos no estrangeiro. O IRS, o IRC e o imposto sobre sucessões e doações contemplam esta situação, mas sempre sem prejuízo de convenções internacionais em que Portugal seja parte. Geralmente as regras de incidência real e pessoal traçam os limites em que se aplicam as leis materiais internas, que normalmente coincidem com as fronteiras do Estado.

A Lei Geral Tributária acolheu o princípio da territorialidade com carácter genérico e na tributação do rendimento optou pela tributação da globalidade dos rendimentos dos residentes em território português, independentemente do local onde sejam obtidos (cfr. artigo $13^{\circ}$.).

\section{CARACTERIZAÇÃO DE ALGUMAS INOVAÇÕES DA LEI GERAL TRIBUTÁRIA}

\subsection{Tributação de rendimentos ou actos ilícitos (cfr. $\operatorname{art}^{\circ} . \mathbf{1 0}^{\circ}$.)}

Não se pretende legalizar os actos ilícitos, mas tão-só materializar o princípio da igualdade tributária já abordado, e não retirar o carácter sancionatório a estes actos. A lei tributária não pode legalizar tais actos, mas pretende tributá-los quando preencham os pressupostos das normas de incidência aplicáveis. Já aconteceu, assim, com o exercício ilegal de actos bancários ou de seguros.

\subsection{Consagração da regra geral da transitoriedade dos Benefícios Fiscais (cfr. $\operatorname{art}^{\circ} .1^{\circ}$.)}

Os benefícios fiscais vigoram por um período de 5 anos e depois cessam, salvo quando tiverem carácter estrutural. $O$ Benefício não vai ser alterado no período, mas os titulares devem revelar à Administração Tributária todos os 
pressupostos e abdicar da confidencialidade, quando concedidos em função dos rendimentos do beneficiário ou do seu agregado familiar.

\subsection{Sujeição a uma regulamentação clara e equilibrada do instituto da} responsabilidade subsidiária, limitando, inclusive, os pressupostos da reversão (cfr. art $^{\circ} .23^{\circ}$. e segts.)

O artigo $13^{\circ}$. do Código do Processo Tributário, revogado pela Lei Geral Tributária, previa a responsabilidade dos gerentes e administradores, cabendo a estes provarem a sua inocência pelo não pagamento das dívidas fiscais vencidas durante o exercício do cargo ou mesmo quando o facto gerador do imposto tenha ocorrido no período das funções de administrador ou gerente. A Lei Geral Tributária mitigou o ónus da prova e houve cisão do artigo $13^{\circ}$. do C.P.T.

Quando houver insuficiência do património, o ónus de provar a culpa dos responsáveis pelas funções de administração cabe à Administração Fiscal. Quando houver falta de pagamento no período do exercício do cargo, o ónus da prova recai sobre os responsáveis pela a administração. A reversão da execução fiscal contra o responsável subsidiário passa a depender de audição prévia, mesmo nos casos em que lhe cabe provar que não houve culpa na falta do pagamento.

A reversão deve ser fundamentada de facto e de direito com a matéria apurada ou confirmada por meio da audição prévia. Em termos de direito comparado, a regra geral vai no sentido da responsabilidade subsidiária dos administradores/gerentes pelas dívidas das sociedades, podendo variar os pressupostos da responsabilidade.

\subsection{Negócio Jurídico simulado (cfr. artigo $39^{\circ}$.)}

A tributação recai sobre o negócio jurídico real e não sobre o negócio jurídico simulado, devendo este ser primeiramente anulado, através de decisão judicial. 


\subsection{Encurtamento pontual ou genérico dos prazos de caducidade do direito de liquidação e de prescrição das obrigações tributárias (cfr. artigos $45^{\circ}$. a $4^{\circ}$.)}

A vida económica é mais célere e são mais sofisticadas as formas de evasão fiscal, justificando-se, deste modo, a redução de prazos. Em Espanha o prazo é de quatro anos e em França de três anos, com a ressalva de fraude fiscal, sendo os prazos de caducidade e prescrição iguais.

Houve a cautela de assegurar que o novo prazo de caducidade começasse só a partir de 98/01/01. Vigoram os prazos estabelecidos na Lei Geral Tributária, porque contrários aos outros prazos estipulados, e quando exista incompatibilidade entre a Lei Geral Tributária, o C.P.T. e restantes códigos, aplica-se aquela. Em caso de erro evidenciado na declaração do contribuinte ou de utilização de métodos indirectos, o prazo de caducidade é apenas de três anos, mas quando há reporte de prejuízos, o prazo de caducidade é o do exercício desse direito. $O$ início de acção de inspecção externa suspende o prazo de caducidade.

O prazo de prescrição passou de dez para oito anos, aplicando-se o artigo $297^{\circ}$. do Código Civil que define o termo da contagem do prazo, quando este seja alterado, cotejando a lei nova, com a lei anterior, com excepção dos impostos abolidos à data da entrada em vigor da Lei Geral Tributária.

Outra novidade consiste no prazo máximo de contagem dos juros de mora que passou para três anos, não sendo comparáveis com os anteriores prazos. $O$ início da contagem do prazo de prescrição coincide com o da caducidade, o que na prática o encurtamento daquele prazo pode não ser para oito anos, mas menos (cfr. artigo $48^{\circ} ., \mathrm{n}^{\circ} .1$ da Lei Geral Tributária e artigo $34^{\circ} . \mathrm{n}^{\circ} .2$, (revogado), do C.P.T.).

A interrupção da prescrição em relação aos responsáveis subsidiários também teve modificações. Por último, referir que com a actual lei a instauração do processo de execução fiscal não interrompe a prescrição, ao contrário do que acontecia no C.P.T.

\subsection{Encurtamento do prazo de caducidade do direito de liquidação em caso de fiscalização por iniciativa do sujeito passivo $\left(\mathrm{cfr} \operatorname{art}^{\circ}, 4^{\circ}\right.$.)}

Esta possibilidade consta de lei especial (cfr. Decreto-Lei $n^{\circ} 6 / 99$, de 8 de Janeiro) e também poderá ser requerida por terceiro que demonstre ter interesse legítimo na fiscalização, com autorização do sujeito passivo. Quando haja fiscalização tributária a solicitação do contribuinte, não podem ser 
praticados posteriormente à notificação das conclusões ao contribuinte novos actos de liquidação, ocorrendo, assim, nessa parte a caducidade.

\subsection{Garantia dos créditos tributários (cfr. artigo $50^{\circ}$.)}

A Lei Geral Tributária estabelece como garantias também o direito de constituição de penhor ou hipoteca legal, devendo o C.P.T. regular estes casos, quando o pagamento se efectuar em prestações.

\subsection{Sujeição da possibilidade de adopção de providências cautelares a} favor da Administração Tributária ao princípio de proporcionalidade e à condição de não causarem dano irreparável ao sujeito passivo (cfr. $\operatorname{art}^{\circ} . \mathbf{5 1}^{\circ}$.)

Quando exista fundado receio de frustração da cobrança dos créditos tributários ou de destruição de documentos ou outros elementos, a Administração Tributária pode tomar providências cautelares, mas agora expressamente subordinadas ao princípio da proporcionalidade.

7.9. Possibilidade de o executado ser isento da prestação de garantia e indemnizado pela prestação de garantia indevida na execução fiscal (cfr. artigos $52^{\circ}$. e $53^{\circ}$.)

Esta situação é inédita, pois consagra-se a dispensa da prestação de garantia quando não haja meios económicos ou causar prejuízos irreparáveis ao executado. A garantia pode ainda ser substituída, reforçada quando se manifestar insuficiente e reduzida nos casos de anulação parcial da dívida ou pagamento parcial.

Estabelece-se o direito à indemnização em caso de prestação indevida da garantia em proporção do vencimento da reclamação, recurso, impugnação ou oposição, incluindo todas as despesas efectuadas até ao montante da aplicação da taxa de juros indemnizatórios prevista na Lei Geral Tributária. O reembolso do custo da garantia quando indevida é comum em países da União Europeia. 


\subsection{Um novo tipo de procedimento (cfr. artigo $54^{\circ}$. e segts.)}

Sem prejuízo da implementação de um novo Código do Processo Tributário e do Regulamento Complementar do Procedimento da Inspecção Tributária que estabelece os direitos e deveres da inspecção tributária e dos sujeitos passivos nas acções de fiscalização, a Lei Geral Tributária dedica grande parte do seu articulado (41 artigos) ao procedimento tributário que compreende toda a sucessão de actos dirigida à declaração de direitos tributários, sendo diferente do conceito de processo.

$O$ ordenamento processual tributário necessitava de um conjunto de normas estruturantes do procedimento tributário, incluindo o âmbito $\mathrm{e}$ princípios fundamentais, artigos $54^{\circ}$. e $55^{\circ}$. Aproveitou-se para adequá-lo ao Código do Procedimento Administrativo, nomeadamente com os limites temporais da revisão dos actos tributários, instituição de um prazo para conclusão do procedimento e clarificação dos regimes da competência, delegação de poderes, legitimidade e prova. $\mathrm{O}$ procedimento tributário tem natureza especial do procedimento administrativo.

\subsection{Alargamento muito substancial dos deveres de colaboração da Administração Tributária com o contribuinte (cfr. artigo 59\%.)}

Esta inovação procedimental alargou as garantias dos contribuintes através de uma nova concepção da cooperação dos sujeitos passivos com a Administração expressamente consagrada no $\mathrm{n}^{\circ}$. 1 do artigo $59^{\circ}$. como recíproca e não unilateral, como em parte se verificava anteriormente.

Cumpre-se o princípio da administração aberta extensivo à Administração Tributária, ficando esta obrigada à publicação das orientações genéricas, à identificação dos responsáveis pela direcção dos procedimentos, à assistência necessária ao cumprimento dos deveres dos contribuintes, ao conhecimento antecipado do início da inspecção da escrita, entre outras obrigações, que são bem demonstrativas da nova concepção de procedimento acolhido pela Lei Geral Tributária.

\subsection{Consagração expressa e regulamentação clara da audiência prévia no procedimento tributário (cfr. artigo $60^{\circ}$.)}

Para além da cooperação mais intensa entre a Administração Fiscal e os contribuintes, também o princípio da participação pode ser visto como uma nova concepção procedimental. O Código do Procedimento Administrativo 
ressalva nos artigos $2^{\circ}$ e $8^{\circ}$. 0 direito da participação - princípio constitucional, entendendo-se que o C. P A. poderá ser lei reforçada, como se referiu anteriormente, razão pela qual a audição prévia não constitui qualquier inovação.

Este procedimento $\varepsilon$ de aplicar aos actos parcial ou totalmente desfavoráveis aos contribuintes e poderá constituir um valioso meio de neutralizar eventuais litígios que só podiam ser dirimidos pela via da reclamação ou impugnação. Os pressupostos do princípio da participação vêm definidos no C.P.A. e compete à Administração Tributária optar pela audição oral ou escrita, embora possa ser prudente deixar-se tal opção ao contribuinte. A audição prévia permite a conjugação entre a eficácia e o contraditório.

\subsection{Clarificação dos poderes da fiscalização tributária e sua sujeição expressa ao princípio da proporcionalidade (cfr. artigo $63^{\circ}$.)}

A Lei Geral Tributária e o Regulamento Complementar do Procedimento da Inspecção Tributária definem os poderes da inspecção tributária, mas não é alterado o actual regime de inoponibilidade do sigilo bancário à Administração Tributária.

Os procedimentos da inspeç̧ão são os adequados e proporcionais aos objectivos a prosseguir, consagrando-se o princípio da irrepetibilidade da acção fiscalizadora externa, que só pode ser afastado caso surjam factos novos, e mediante autorização do dirigente máximo do serviço. Estabelecem-se as causas legítimas de oposição do contribuinte às acções de fiscalização e quando e como a Administração Tributária pode realizar a diligência, isto $\varepsilon$, só mediante intervenção judicial, com base em pedido fundamentado.

\subsection{Inversão das regras gerais do ónus da prova no procedimento tributário, quando haja indícios fundados de a matéria tributável real não corresponder à declarada (cfr. artigo 74\%.)}

A lei Geral Tributária procedeu ao equilíbrio do ónus da prova entre o contribuinte e a Administração Tributária. Quando a matéria tributável seja determinada com recurso a métodos indirectos, compete à Administração Tributária o ónus da prova da verificação dos pressupostos da sua aplicação e ao sujeito passivo cabe demonstrar que existe excesso na quantificação da respectiva matéria tributável. 


\subsection{Revisão dos actos tributários (cfr. $\operatorname{art}^{\circ} .7^{\circ}$.)}

Os actos tributários só podem ser revistos ou anulados parcial ou totalmente nos prazos de reclamação graciosa ou impugnação judicial. Por iniciativa da Administração Tributária podem ser revistos no prazo de quatro anos após a liquidação ou a todo tempo se o tributo não estiver pago. Sem prejuízo das respectivas garantias, o erro na autoliquidação, para efeitos de revisão dos actos tributários, considera-se imputável aos serviços.

A revisão em prazos demasiado longos ou a todo o tempo não favorece a eficiência da Administração Tributária, para além de não contribuir para a estabilidade das relações juridico-tributárias.

A Lei Geral Tributária introduziu uma medida excepcional, podendo o dirigente máximo dos serviços autorizar nos três anos posteriores ao do acto tributário a revisão da matéria tributável apurada com fundamento em injustiça grave ou notória, quer para o contribuinte quer para a Fazenda Nacional. Acolheu-se uma medida que constava da reforma fiscal dos anos sessenta, mas que não foi produzida para a reforma fiscal de 1989.

\subsection{Definição dos princípios fundamentais de avaliação directa e indirecta da matéria tributável (cfr. artigo $81^{\circ}$. e segts.)}

A matéria tributável é avaliada directamente, podendo ser objecto de avaliação indirecta, por parte da Administração Tributária, nos casos tipificados na lei. A subsidiariedade da avaliação indirecta perante a avaliação directa, a obrigatoriedade de a avaliação se basear em critérios objectivos que devem constar da fundamentação, a participação do contribuinte nas avaliações e os pressupostos da realização das avaliações, passaram a ser regras estruturantes do novo quadro do sistema de avaliações.

\subsection{Clarificação das condições de avaliação indirecta da matéria colectável (cfr. artigos 87 e segts.)}

A lei Geral Tributária também clarificou o quadro da avaliação indirecta, pretendendo clarificar a legislação em vigor, sem pôr em causa os seus princípios fundamentais.

Tipificou os comportamentos ilegais dos sujeitos passivos que se traduzem basicamente em a sua matéria colectável se afastar para menos, sem razão justificada, da que resultaria da aplicação dos indicadores objectivos da actividade de base técnico-científica, como margens de lucro ou rentabilidade 
significativamente inferiores às normais do exercício da actividade, estabelecidos pelo Ministro das Finanças após audição das associações empresariais. O contribuinte pode apresentar razões justificativas desse afastamento na declaração ou por meio de audição prévia, podendo ter tratamento específico, desde que não tenham decorrido mais de três anos sobre o início da actividade.

A lei estabelece alguns elementos a ter em conta na determinação da matéria tributável por métodos indirectos, alguns dos quais se encontram estabelecidos nos códigos do imposto sobre o rendimento. A solução adoptada é comum à dos restantes países da União Europeia que, de certo modo, já cabia dentro de uma interpretação razoável dos códigos referidos, muito embora seja discutível, na lei anterior, a aplicação de métodos indirectos com base em prejuízos reiterados ou lucros abaixo dos índices.

\subsection{Substituição das actuais comissões de revisão por um diálogo directo entre o Fisco e o contribuinte (cfr. artigos $91^{\circ}$. a 94.)}

Assiste ao contribuinte o direito de colocar em crise a matéria colectável fixada por métodos indirectos. O pedido de revisão é apreciado através de diálogo directo por duas cabeças (perito indicado pelo contribuinte e perito da Administração Tributária), com a participação do perito independente quando o houver, procedendo-se à supressão da figura do presidente das comissões de revisão.

Os peritos passam a conhecer e a apreciar os pressupostos da aplicação dos métodos indirectos, o que não acontecia na anterior legislação e passa a existir a obrigatoriedade de autuação de um único procedimento de revisão em caso de apuramento da matéria colectável de um ou mais exercícios.

Em caso de acordo, a Administração Tributária não pode alterar a matéria colectável, salvo em caso de crime de fraude fiscal, mas o contribuinte também não pode impugnar a liquidação com base em ilegalidade na determinação da matéria tributável determinada com base em avaliação indirecta.

Em caso de falta justificada do perito do contribuinte, a lei continua a determinar que o órgão da Administração Tributária marque nova reunião para o quinto dia subsequente.

Se o parecer do perito independente, que não é juridicamente vinculativo, for conforme ao do perito do contribuinte e a Administração Tributária resolver em sentido contrário, a reclamação graciosa ou impugnação têm efeito suspensivo na parte em que os peritos estiverem de acordo, independentemente da prestação da garantia. 
À Comissão Nacional compete a elaboração e correcção das listas de peritos independentes e pode apresentar recomendações à Administração Tributária.

\subsection{O princípio do inquisitório no processo tributário (cfr. artigo 99.)}

No processo tributário o tribunal tem jurisdição plena, isto é, não se deve limitar só aos factos do processo, mas deverá apreciar todos os outros factos, ordenando as diligências e investigações úteis para conhecer a verdade relativamente aos factos alegados, o que se chama o princípio do inquisitório. Ao contrário do processo civil, em que o tribunal se limita só aos factos, isto é o princípio do dispositivo.

Este procedimento encontra-se igualmente regulado no procedimento tributário, não se encontrando a Administração Tributária subordinada à iniciativa do autor do pedido, podendo realizar as diligências necessárias à descoberta da verdade material (cfr. artigo $58^{\circ}$.).

7.20. Natureza judicial do processo de execução fiscal (cfr. artigo $103^{\circ}$.)

O processo de execução fiscal deixa de ter natureza administrativa e passa a ter natureza judicial, terminando-se com a indefinição da sua natureza administrativa ou judicial após subida ao tribunal para apreciação de recursos, e após decisão baixar à repartição de finanças para se continuar a respectiva tramitação.

\subsection{Litigância de má fé (cfr. artigo $104^{\circ}$.)}

A Administração Tributária pode ser condenada numa sanção pecuniária, no caso de actuar em juízo contra o teor de informações vinculativas prestadas aos interessados ou o seu procedimento divergir do habitualmente adoptado em situações semelhantes. 


\subsection{Infraç̧ões físcais (cfr. artigo $106^{\circ}$. e segts)}

São indicadas as regras fundamentais sobre as infracções fiscais, sendo remitido para diploma próprio (eventual revisão e fusão das infracções fiscais aduaneiras e não aduaneiras num só diploma) a definição do tipo de crime, contra-ordenação fiscal, sanções e regras de procedimento.

É definida a responsabilidade solidária e subsidiária dos administradores e outros responsáveis pelas multas ou coimas aplicadas às pessoas colectivas.

Para determinação do montante da coima a aplicar, o beneficio económico obtido com a prática da infracção deve ter em consideração os juros compensatórios e demais encargos legais.

As sanções principais e acessórias previstas na lei para as infracções fiscais passam a ser da competência de uma Comissão de Infraç̧̃es Fiscais nomeada pelo Ministro das Finanças.

\section{CONCLUSÃO}

A publicação da Lei Geral Tributária veio enriquecer o sistema fiscal português, pondo cobro a uma necessidade que se sentia há muito, ficando, deste modo, mais completo o edifício jurídico fiscal. A exemplo do que acóntece em muitos países da União Europeia, este diploma dève ser também factor de desenvolvimento e aperfeiçoamento do sistema fiscal, o que seguramente acontecerá quando os códigos fiscais e demais normas tributárias se adaptarem à presente lei.

A Lei Geral Tributária é a Constituição Material da Fiscalidade ou, como já lhe chamam, a Bíblia Fiscal. Acolheu princípios fundamentais insertos na Constituição ou na lei ordinária, mas não revoga normas especiais, nem normas de Direito Comunitário. Não tem prevalência sobre as restantes leis, não se considerando lei reforçada.

Procedeu à classificação dos tributos e definiu os seus pressupostos, mas não regula as taxas e as contribuições financeiras, porque a doutrina não está suficientemente desenvolvida, existindo incertezas e zonas cinzentas entre taxas e impostos.

As normas constantes da presente lei têm como objectivo habilitar o intérprete do Direito Tributário com as ferramentas para a sua aplicação e diminuir a incerteza e insegurança na actividade tributária, razão de ser da abordagem de alguns conceitos no presente documento.

Não há apenas questões garantísticas, estabelecendo a lei um equilíbrio, no patamar superior, entre as garantias dos contribuintes e as prerrogativas da Administração Tributária. 
É objecto da presente lei a definição dos princípios gerais e fundamentais da ordem tributária, a regulação da relação jurídica tributária, do procedimento tributário, que deverá obedecer aos princípios da legalidade, da igualdade, da proporcionalidade, da justiça, da imparcialidade e da celeridade, a consagração do acesso à justiça e dos princípios do sistema sancionatório tributário.

A presente lei contempla aproximadamente cinquenta inovações, apresentando traços de clivagem que traduzem alguma ruptura relativa.

A regulamentação equilibrada do instituto da responsabilidade subsidiária, o encurtamento dos prazos de caducidade do direito de liquidação e de prescrição das obrigações tributárias, que implica mais eficácia e eficiência da Administração Tributária, a instituição de nova disciplina para as providências cautelares a favor da Administração Tributária e da prestação de garantia, o alargamento do dever de colaboração recíproco entre a Administração Tributária e os contribuintes, o acolhimento do princípio da participação dos contribuintes na formação das decisões que thes digam respeito, a sujeição expressa da fiscalização tributária ao princípio da proporcionalidade, a irrepetibilidade da aç̧ão fiscalizadora externa, a inversão das regras gerais do ónus da prova no procedimento tributário, a revisão dos actos tributários, a definição dos princípios fundamentais da avaliação directa e da avaliação indirecta da matéria tributável, a substituição das actuais comissões de revisão da matéria colectável, a instituição do princípio do inquisitório e a diferença entre o procedimento tributário e o processo tributário, são apenas alguns exemplos das inovações plasmadas na Lei Geral Tributária.

O êxito desta lei ou de qualquer outra depende em muito da forma como os aplicadores e intérpretes introduzam as inovações e as interiorizem, sendo importante o grau de abertura na aplicação e enquadramento das normas.

\section{NOTAS}

* Texto elaborado, em Fevereiro/99, para apoio a um curso de formação e à disciplina de Fiscalidade do $2^{\circ}$ Semestre do ano lectivo de 1998/99.

${ }_{1}^{1}$ Teixeira Ribeiro, Finanças Públicas, Coimbra Editora, Ld'., 1988.

${ }^{2}$ Nuno Sá Gomes, Lições de direito fiscal, DGCI, 1986.

${ }^{3}$ Nuno Sá Gomes, idem.

${ }^{4}$ Idem.

${ }^{5}$ Nuno Sá Gomes, idem.

${ }^{6}$ Martinez, Pedro Soares, Manual de Direito Fiscal, Almedina - Coimbra, 1996. 


\section{BIBLIOGRAFIA}

ARMAND, Paul e Pironin, Henry, Guide du Créateur d' Entreprise (1995), Top Editions, Paris,.

BOTELHO, José Santos, ESTEVES, Américo Pires e PINHO, José Cândido (1992), Código do Procedimento Administrativo, Livraria Almedina, Coimbra.

BRAZ, António Teixeira (1986), Princípios do Direito Fiscal, Almedina, Coimbra.

CAMPOS, Diogo Leite, RODRIGUES, Benjamim e SOUSA, Jorge Lopes (1999), Lei Geral Tributária, Vislis Editores, $\mathrm{Ld}^{\mathbf{a}}$. Lisboa.

CANOTIlHO, J. J. Gomes e MOREIRA, E. Vital (1997), Constituição da República Portuguesa, Coimbra Editora, Coimbra.

CORTE-REAL, Carlos Pamplona, Curso de Direito Fiscal, Cadernos de C.T. F., nº 124

GOMES, Nuno Sá (1997), Manual de Direito Fiscal, Editora Rei dos Livros, Lisboa.

GOMES, Nuno Sá (1986), Lições de Direito Fiscal, DGCI.

MARTINEZ, Pedro Soares, Direito Fiscal (1996), Almedina, Coimbra.

MERCIER, Jean-Yves e PLAGNET, Bernard (1998/1999), Les Impôts en France, Traité de Fiscalité, Editions Francis Lefebvre.

NETO, Abílio (1997), Código Civil, Ediforum, Edições Jurídicas, Ldª ., Lisboa.

RIBEIRO, José Joaquim Teixeira (1988), Liçôes de Finanças Públicas, Coimbra Editora, Ld. ${ }^{\mathbf{z}}$, Coimbra.

SANTOS, António Carlos (1999), Da Questão Fiscal à Reforma da Reforma Fiscal, Editora Rei dos Livros, Lisboa.

XAVIER, Alberto (1974), Manual de Direito Fiscal, Lisboa.

Revista Ciência e Técnica Fiscal - DGCI. 